\title{
VASCULITE REUMATOIdE COM EVOLUÇÃo CUTÂNEA GRAVE
}

Regina Alice Fontes Von Kirchenheim ${ }^{1}$, Jamille Nascimento Carneiro ${ }^{1}$, Luciana Alves de Almeida ${ }^{2}$, Francisco Aires Correa de Lima ${ }^{3}$, Lícia Maria Henrique Mota ${ }^{4}$, Cezar Kozak Simaan ${ }^{4}$, Rodrigo Aires Correa de lima4, Talita Yokoy de Souza 5 , Francielli de Sousa Rabelo 5

Trabalho elaborado no Serviço de Reumatologia do Hospital Universitário de Brasília (HUB) - Universidade de Brasília (UnB), Brasília, DF

\section{INTRODUÇÃO}

A vasculite reumatoide (VR) é uma condição rara e grave. Os achados cutâneos podem ser bastante variados. Descrevemos um raro caso de vasculite reumatoide com evolução cutânea grave.

\section{Relato de caso}

Mulher, 49 anos, com diagnóstico de AR há 15 anos, em tratamento com metotrexato $15 \mathrm{mg} /$ semana e prednisona $10 \mathrm{mg} / \mathrm{dia}$. Procurou o HUB, relatando, há oito dias, edema e manchas violáceas em perna direita, confluentes, intensamente dolorosas, com vesículas e bolhas de conteúdo seroso. O quadro sugeria erisipela bolhosa, sendo iniciada antibioticoterapia. Em três dias as lesões progrediram para grandes bolhas e úlceras com exsudação e material necrótico. Exames laboratoriais: hemoglobina de 7,7 g/dl, leucometria de 16.400, VHS:60 mm/h e PCR: 35 mg/dl. Biópsia da lesão:

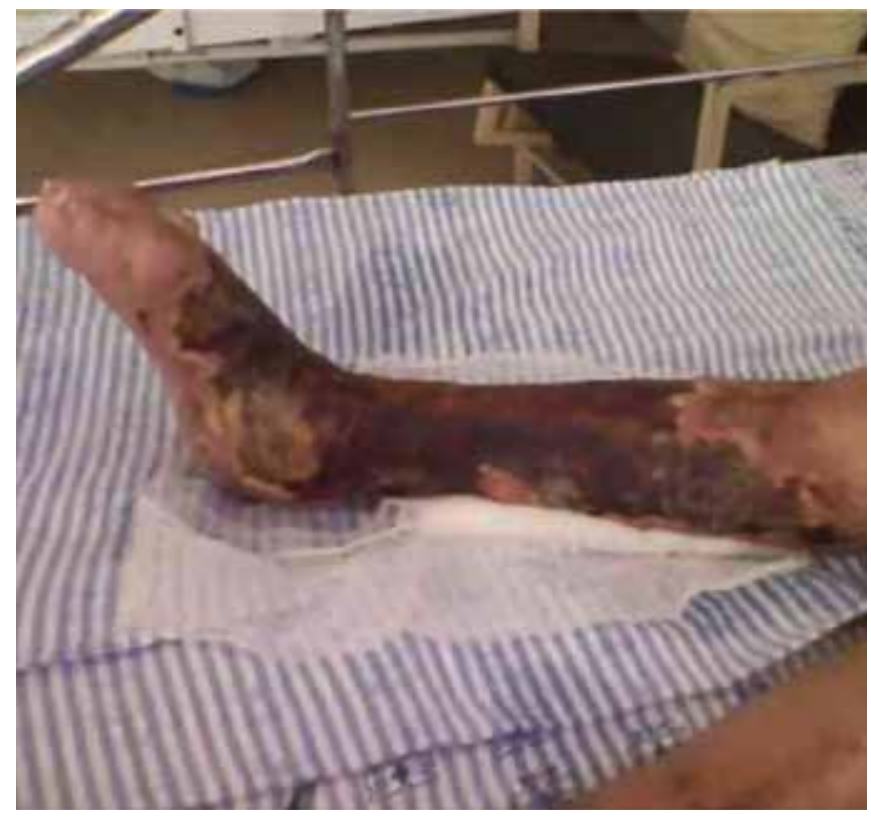

intenso infiltrado neutrofílico na derme profunda e tecido subcutâneo, sinais de vasculite neutrofílica em pequenos vasos (necrose fibrinóide da parede, trombose e hemorragia). A cultura de fragmento cutâneo, bem como a hemocultura mostraram Acinetobacter baumanii. Diante do diagnóstico de VR cutânea, com quadro infeccioso subjacente, iniciou-se prednisona $1 \mathrm{mg} / \mathrm{kg} / \mathrm{dia}$, ciclofosfamida, via oral, e pentoxifilina. O esquema antimicrobiano foi alterado para imipenem e vancomicina. Houve rápida piora do quadro cutâneo, com necrose extensa dermo-epidérmica e ampla exposição de fáscia e planos musculares profundos, em toda a extensão de membro inferior direito, abaixo do joelho. Optou-se por pulsos de metilprednisolona $500 \mathrm{mg} /$ dia por três dias, indicado desbridamento cirúrgico amplo das lesões, além de oxigenioterapia hiperbárica. Após um mês da terapia, houve surgimento de tecido de granulação, o que possibilitou o planejamento de terapia cirúrgica (enxertia) para recobrir a extensa área de necrose.

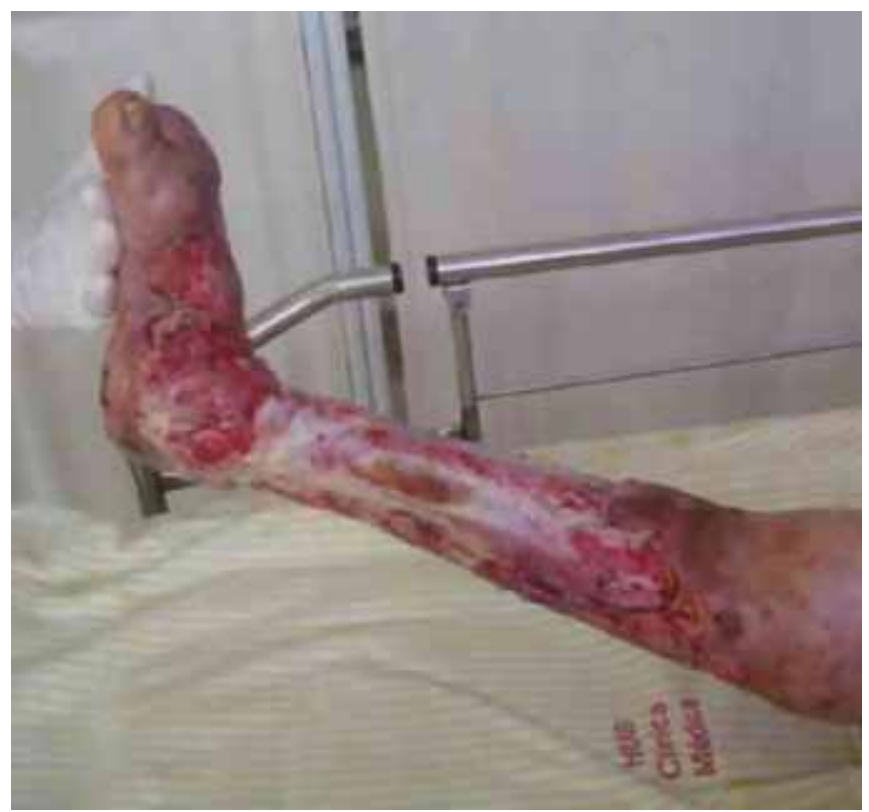

\footnotetext{
1. Residente do $2^{\circ}$ ano de Reumatologia, Brasília, DF

2. Médica estagiária em Reumatologia, Brasília, DF

3. Médico reumatologista, Brasília, DF

4. Médicos reumatologista assistente do Hospital Universitário de Brasília, Brasília,DF

5. Residente do $1^{\circ}$ ano de Reumatologia, Brasília,DF
} 


\section{Discussão}

Relatamos um caso raro de VR cutânea extremamente agressiva, com necrose dermo-epidérmica extensa e exposição de planos musculares, documentado com biópsias e fotografias. Trata-se de um quadro pouco frequente, em que, além da corticoterapia em altas doses e da imunossupressão, o tratamento da infecção subjacente, o desbridamento cirúrgico amplo e o uso de oxigenioterapia hiperbária são essenciais para o tratamento.

\section{REFERÊNCIAS}

1. Scott, DG, Bacon, PA, Tribe, CR. Systemic rheumatoid vasculitis: a clinical and laboratory study of 50 cases. Medicine (Baltimore). 1981;60(4):288-97.

2. Voskuyl, AE, Zwinderman, AH, Westedt, ML, Vandenbroucke JP, Breedveld FC, Hazes JM. Factors associated with the development of vasculitis in rheumatoid arthritis: results of a case-control study. Ann Rheum Dis. 1996;55(3):190-2.

3. Vollertsen, RS, Conn, DL, Ballard, DJ, Ilstrup DM, Kazmar RE, Silverfield JC. Rheumatoid vasculitis: survival and associated risk factors. Medicine (Baltimore) 1986;65(6):365-75

4. Sayah, A, English, JC. Rheumatoid arthritis: A review of the cutaneous manifestations. J Am Acad Dermatol. 2005;53(2):191-209; quiz 210-2.

5. Mongan, ES, Cass, RM, Jacox, RF, Vaughen JH. A study of the relation of seronegative and seropositive rheumatoid arthritis to each other and to necrotizing vasculitis. Am J Med. 1969;47(1):23-35.

6. Glass, D, Soter, NA, Schur, PH. Rheumatoid vasculitis. Arthritis Rheum. 1976;19(5):950-2.

7. Oien, RF, Hakansson, A, Hansen, BU. Legulcers in patients with rheumatoid arthritis--a prospective study of aetiology, wound healing and pain reduction after pinch grafting. Rheumatology (Oxford). 2001;40(7):816-20.

8. Scott, DG, Bacon, PA. Intravenous cyclophosphamide plus methylprednisolone in treatment of systemic rheumatoid vasculitis. Am J Med. 1984;76(3):377-84.

9. Genta MS, Genta RM, Gabay C. Systemic rheumatoid vasculitis: a review. Semin Arthritis Rheum. 2006;36(2):88-98.

10. Hata T, Kavanaugh A. Rheumatoid arthritis in dermatology. Clin Dermatol. 2006;24(5):430-7.

11. Sayah A, English JC 3rd. Rheumatoid arthritis: a review of cutaneous manifestations. J Am Acad Dermatol. 2005;53(2):191-209; quiz 210-2.

\section{*Correspondência:}

SQSW 304 - Bloco A - Apto. 509

Setor Sudoeste

Cruzeiro-DF

70673-401
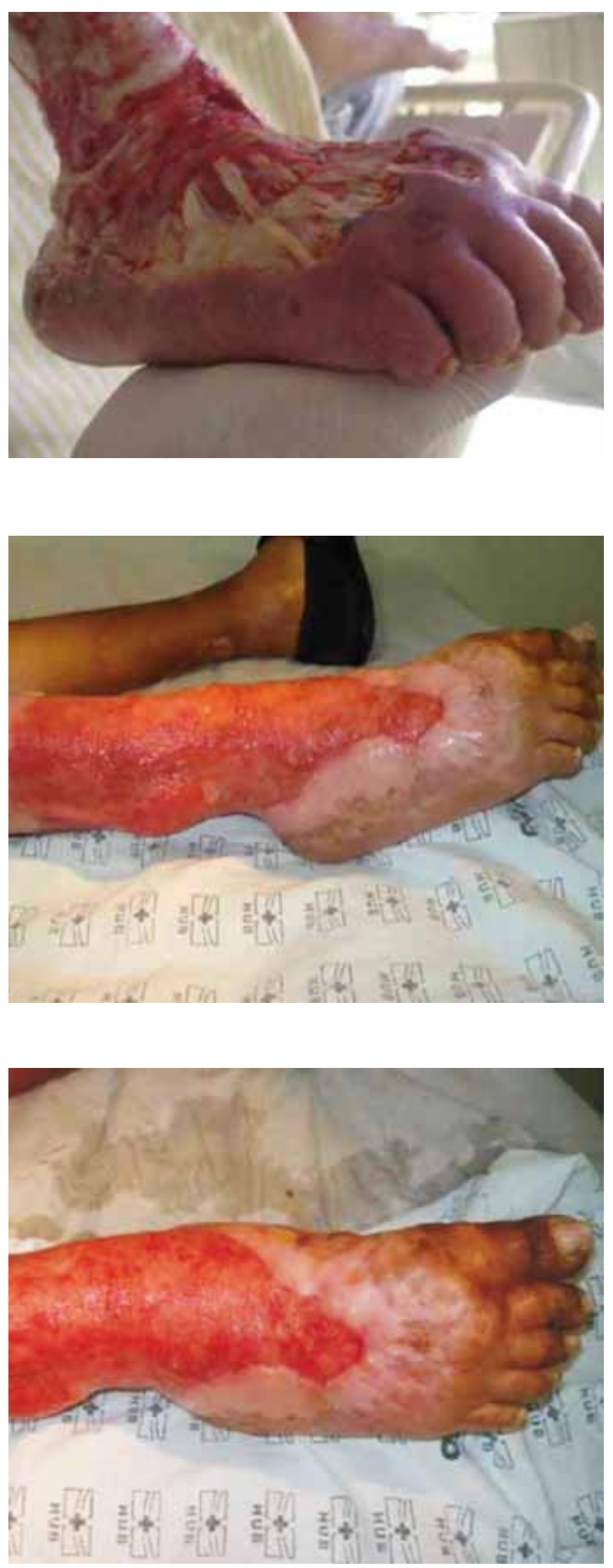